\title{
Apontamentos etnográficos sobre o Cururu e o Siriri de Mato Grosso
}

\section{Ethnographic notes on the Cururu and Siriri of Mato Grosso}

Marta Martines Ferreira ${ }^{1}$ 


\section{Resumo}

Neste artigo analisamos as práticas de reinvenção na sociabilidade festiva do cururu e siriri, duas danças bastante difundidas em Mato Grosso, região Centro -Oeste do Brasil. Refletimos sobre as demandas de apropriação dos grupos por novos espaços urbanos e a ampliação dos momentos festivos, especialmente a participação em festivais, bem como as alterações nas formas e nos conteúdos performáticos desses grupos.

Palavras-Chave: Cururu. Siriri. Sociabilidade. Momentos Festivos.

\section{Abstract}

In this article, we analyze the practices of reinvention in the festive sociability of cururu and siriri, two very widespread dances in Mato Grosso, Midwest region of Brazil. We reflect on the demands of appropriation of the groups for new urban spaces and the expansion of the festive moments, especially the participation in festivals, as well as the changes in the forms and the performative contents of these groups.

Keywords: Cururu. Siriri. Sociability. Festive Moments.

ISSN: $1808-3129$

1 Graduada em Educação Artística com Habilittação em Música - Mestra em Estudos de Cultura Contemporânea - Doutoranda em Arte e Cultura Contemporânea - pela UERJ Universidade do Estado do Rio de Janeiro. Professora efetiva da rede pública do Estado de Mato Grosso UERJ - Universidade Estadual do Rio de Jameiro - Brasil mm mt2000@hotmail.com 


\section{Introdução}

A história da humanidade é permeada de conquistas, conflitos, expropriações, mitos heroico-fundadores e são contadas, quer pela necessidade de preservar tradições, quer por idealizações identitárias. Ao olharmos os ciclos temáticos ritualísticos no Brasil, percebemos um amplo e colorido leque festivo de celebrações. Seja herdado dos costumes das grandes embarcações que atravessaram o oceano, seja da cultura indígena que aqui existia, ou dos batuques da escravidão. Em homenagem aos santos ou não, essas festas são realizadas desde as menores comunidades aos grandes centros urbanos. Vários festejos vêm assumindo o caminho das grandes proporções midiáticas, especialmente quando se fala em entretenimento de massa.

Os sentidos que estas danças atribuem a si mesmas, se dão a partir da articulação constante com os meios de comunicação, proporcionados sobretudo, pelo advento das tecnologias midiáticas e sugerem um discurso construído a partir do "uso dos novos meios de comunicação cujas tecnologias se tornaram mais acessíveis" (GUSHIKEN, 2009, p. 02). A mídia passa então a contribuir para novas permanências da cultura na esfera pública, como uma instância organizadora da cultura popular, na qual o mito ganha um novo contexto e mantém sua existência. Grupos que até então estavam restritos a espaços periféricos, passam à ocupação física de novos espaços urbanos, "as tradições se reinstalam mesmo para além das cidades: em um sistema interurbano e internacional de circulação cultural" (CANCLINI, 2008, p. 218).

Essas festas são o vetor desse processo de acomodação coletiva da religiosidade da população e se tornam também, lugar de memória na construção e atualização na modernidade. É como se uma festa acontecesse dentro da outra; a institucionaliza, organizada pelos grupos multimidiáticos e políticos e as que continuam acontecendo espontaneamente pelos grupos locais em rompimento com o cotidiano e, dessa forma, encontram uma maneira de continuamente recontar sua história, suas lendas, seus mitos. Aquilo que no passado acontecia nos quintais das casas ao redor de fogueiras, hoje é remodelado para os festivais. Um contar continuamente atualizado e contextualizado, partilhado por grupos locais e imaginário social, em ampliação contínua de seus protagonistas. Para esse novo público, novos espaços. Dessa forma, a multidão entra em contato com a tradição em festa ampliada.

Nesse processo em constante movimento, continuam enraizados no seu chão, no seu local de origem, porém sem perder de vista o mundo globalizado. Trigueiro (2005) afirma que, "estamos vivendo num mundo em que quase tudo se torna espetáculo. Vivemos numa sociedade midiatizada onde as culturas populares são atrativos para o exibicionismo" (p. 04) e que essas manifestações populares, já não pertencem mais aos seus protagonistas. Em negociações por diferentes sujeitos em dialéticas conflituosas e paradoxais, se reinventam para as demandas de consumo da sociedade midiática. Para Debor (2003) uma sociedade mediada por imagens, projeta no espetáculo a afirmação de uma vida até então negada "que se tornou visível" (p.16). Essa sociedade transforma o espetáculo em mercadoria diante do mundo global e, nesse movimento "um produto que existe numa forma pronta para o consumo, pode tornar-se, de novo, matéria-prima de outro produto" (MAX, apud DEBOR, 2003, p. 
123). Segundo Debor (2003), o espetáculo "chega à ocupação total da vida social" (p.32), como mediador desse produto modificado.

Desta feita, amplia-se o lugar da festa.

\section{O Cururu e o Siriri entre viajantes e folcloristas}

Sob a ótica dos colonizadores, etnólogos, folcloristas e viajantes estrangeiros, Moutinho (1879), Karl Steinen (1940), Couto de Magalhães (1897), Max Schimidit (1942), Antônio Americano (1925), Mario de Andrade (1942), Antônio Cândido (1976) Ramos \& Drummond (1978), temos acesso a certa documentação, senão farta, ao menos nos sugere um vasto universo simbólico associado às danças em terras brasileiras. Várias são as análises e narrativas a respeito do Cururu e Siriri principalmente no que diz respeito a terminologia linguística ${ }^{1}$. Textos que atribuem sentido a essa arte do fazer que representam a cultura tradicional do Estado de Mato Grosso, partes do Estado de Mato Grosso do Sul e áreas do médio Tietê paulista. Configurações que passam da dança religiosa recreativa, à modalidade caipira, supostas a partir das relações de tempo e lugar, segundo suas relações de poder².

Cuiabá, cujo povoamento se deu a partir das lavras de ouro, era pequena e pobre, embora capital da Província em 1835. Com uma população de onze mil habitantes, entre livres pobres, brancos, escravos e libertos, além da falta de organização na sua formação geográfica, não contava com um plano de crescimento e ordenamento local. Aos poucos inicia certo desenvolvimento, expandindo-se e adquirindo novas formas em sua organização espacial.

As tentativas de controlar o crescimento da população e a ocupação desordenada dos espaços urbanos como as ruas, travessas, becos e chafarizes, nos remetem à aprovação do Código de Posturas da cidade, sancionado pelos dirigentes políticos em 04 de janeiro de 1831. Continha entre outras medidas, a proibição da prática do cururu sob pretexto de prevenir desordens, brigas e assassinatos que ocorriam nesses ajuntamentos (APEMT, DOC. 01). Todo e qualquer ajuntamento, inclusive os entrudos, os batuques e as rodas de brinquedos ${ }^{3}$ ou função ${ }^{4}$ de cururu, eram vistos como momentos em que pessoas livres, pobres, escravos e libertos articulavam-se para execução de crimes de toda natureza. Forma-se sob o folguedo a partir de então, um campo imaginário no qual o transforma em algo ameaçador e perigoso ao bem estar da população cuiabana.

Essas verdades são forjadas a partir dos discursos contidos nos inquéritos policiais, nos quais se encontram registrados a repressão policial, conforme relato dos chefes de polícia aos presidentes da Província de Mato Grosso, a partir da aplicação

\footnotetext{
1 Cujo corpus lexical vernáculo, marcam 1562 como o início da ordenação alfabética do vocabulário português. 0 efetivo convívio linguístico do português com outras línguas europeias, se deu no espaço da Península Ibérica, cujo corpus trilíngue se dicionariza no século XVII. Dessa intercomunicação de ínguas, registra-se um vocabulário básico de mais de 11.000 mil formas. Esses dicionários são uma fonte privilegiada especialmente para a história da língua e da cultura. Oferecem além disso uma espécie de roteiro verbal para o reconhecimento dos contatos internacionais e da intercomunicação. (VERDELHO, 2011).

2 Para Certeau o "poder tem sua lógica (...) o discurso ideológico se ajusta a uma ordem social (...) É um mesmo movimento que organiza a sociedade e as "ideias" que nela circulam" (CERTEAU, 1982, p. 69/70).

3 Diz-se brincar; o ato de fazer Cururu que é também o mesmo que festar, "Eu já brinquei muito com Fulano, ou "Fui numa brincadeira lá no Mimoso" (RAMOS \& DRUMMOND, 1978, p. 12).

4 Terminada a louvação, inicia-se a função onde os cururueiros se divertem com os repentes, sobre temas de suas vivências, momento que exige-se grande habilidade no improviso.
} 
da lei em 16 de dezembro de 1860. Conforme a seguinte ocorrência, "das partes recebidas hoje nesta Secretaria consta que hontem pelas dose horas da noite fora preso e recolhido na Cadeia o escravo Mathias, de propriedade de D. Marianna, por ser encontrado em uma função de cururú na rua da Fé, sem bilhete de sua senhora (APEMT, DOC. 02).

A chamada elite local, apesar do número reduzido, era poderosa em relação a população de livres pobres, escravos e libertos. Impunham uma ação de política de controle que evidencia um campo no qual permitiu que esses sujeitos estabelecessem "alianças na construção de equilíbrios possíveis, no jogo de forças que thes era intensamente desfavorável" (VOLPATO, 1993, p. 232). Os marginalizados agiam inspirados ou pressionados pelas contingências da vida, apesar de todas as restrições a que estavam submetidos.

\begin{abstract}
Mesmo porque a prisão correcional de bêbados, turbulentos, escravos que frequentavam batuques e cururus, sem bilhetes de seus senhores, prostitutas, enfim, toda uma legião de transgressores que não respeitavam o toque de recolher, estimulados pela falta de uma boa iluminação da cidade, (...) em cuja esteira vinham as brigas e a violência, mas que também era uma poderosa arma para nivelar as diferenças sociais e aproximar brancos e negros, livres e escravos (MACHADO FILHO, 2006, p. 31).
\end{abstract}

Nota-se, que apesar da imposição proibitiva da lei através da repressão policial e prisão dos brincantes do cururu, isso não os impedia de se insubordinarem contra os mecanismos de controle do poder. Pelo contrário. Esses indivíduos davam vazão aos seus desejos e sentimentos, ao mesmo tempo em que se constituíam como sujeitos históricos ao promoverem o cururu e outras festas à revelia de qualquer proibição ou repressão policial. E se por um lado, o Código de Posturas delimitava a prática do cururu, por outro, é fato que não alcançava a eficácia desejada, já que sair escondido para se divertir em cururus era comum entre os cativos e constituía uma das formas que encontravam para circular pela capital da província,

\footnotetext{
Os escravos iam e vinham pelas ruas de Cuiabá durante a noite e não deixavam de participar de festas e ajuntamentos, toques de viola e jogos de cartas. Para satisfazer esse pequeno desejo de se divertir durante a noite, colocavam-se à mercê da ação da polícia, sujeitos a castigos físicos e a prisão. Mesmo assim, não deixaram de dar vazão a essa pequena vontade. Ao infringir a lei para satisfazer um gosto, o escravo estava, mesmo não consciente disso, atuando como sujeito e contestando a afirmação de que o homem submetido ao domínio de outro era o 'mesmo que um morto', desprovido de vontade (VOLPATO, 1993, p. 160).
}

De qualquer maneira, esses registros apontam o cururu, inserido em um contexto amplo e ambíguo. Do ponto de vista desses relatos, é possível conhecer melhor suas caraterísticas e os elementos estruturantes como seu regionalismo e possíveis transformações históricas. A importância desses relatos, se fixam justamente no registro de práticas por muitos ignoradas, por estarem ligadas às populações de pobres e negros livres ou escravos. Esses registros apontam relevantes informações sobre a música e a dança cultivados nesse período e espaço geográfico.

Cururu, uma dança arrodeada, formada por cantadores e tocadores de frente 
para o altar. Tocam e cantam em versos, num movimento de entrelaçar as pernas e revoltear os corpos batendo os pés, giram ritmadamente da esquerda para a direita "dando um passo e parando; dois passos e parando por fração de segundo; depois mais três pequenos passos" (RAMOS \& DRUMMOND, 1978, p. 14), para recomeçarem novamente, no ritmo da viola e do ganzá. Enquanto isso outros dançam entre si, em meio a gingados e movimentos corporais. Assim que chega a bandeira do santo, os cantadores ajoelham-se diante do altar arrumado no canto da casa do festeiro e iniciam a louvação, "a festa é para o santo, pode ser Santo Antônio, São Pedro, Senhor Divino, São Benedito, qualquer um. É o santo da devoção do dono da casa que comemora sua data todos os anos" (RAMOS \& DRUMMOND, 1978, p.12).

Uma dança constantemente presente nas festas católicas tradicionais, cujas descrições apontam que após a louvação dos santos, iniciam-se os desafios que tanto são da ordem religiosa, quanto profana. Cândido (1976) nos diz que de um lado, os grupos indígenas incluíam na sua vida religiosa elementos tomados ao Cristianismo, de outro, a catequese assumiu certo compromisso com a cultura local e, de forma regular o que se deu foi a "incorporação de práticas mágico-religiosas do aborígene à sociedade formada pela catequese e a fusão de raças e culturas, quer como sobrevivência, a título de superstição, quer em certos casos, pela tolerância estratégica do catequista" (p. 41/42). Reforça a crença de ser o cururu uma dança originalmente ritualística de povos indígenas, considerando a existência de representações místicas sobre a origem do fogo. Cururu na língua tupi, significa sapo grande, engolidor de fogo.

Enquanto modalidade de cultura do povo, o cururu sob o aspecto de gênero musical, não conta com autoria individualizada, entretanto, do ponto de vista criativo, atua como projeto individual pautado nas habilidades artísticas de cada membro do grupo. Cabe ressaltar o papel do cururueiro ${ }^{5}$ como o principal porta voz do cururu. Sua notoriedade o coloca como figura de grande importância junto a sua comunidade. Desta feita, atrai para si grande distinção, pois executar a viola com destreza enquanto formula os desafios aos companheiros é sempre visto como algo superior, "os cantadores estão avisados. Somente cantador de alguma sabedoria, que brincadeira para o santo precisa ter ciência, tem que saber fazer as saudações, não pode ser na base do lari-lai-á" (RAMOS \& DRUMMOND, 1978. p. 03, Grifo dos autores).

Os versos, são de domínio público, podem ser da tradição ou improvisados no momento, "o verso é sempre trovado, rimado. Já a toada, quase nunca tem rima" (RAMOS \& DRUMMOND, 1978. p. 03), ao contrário do verso, a toada tem um dono e é sempre respeitada pelos demais cururueiros. Ramos e Drummond (1978) trazem um exemplo,

VERSO

\author{
Glorioso Pai do mundo, ai, ai \\ Pai de todo pecador, ai, ai
}

5 Os cantadores e tocadores de viola-de-cocho, tanto no cururu como no siriri, são conhecidos por cururueiros. 
Sou eu que não mereço os seus agrados

Menina dos olhos mortos

Sobrancelha de veludo

Quero tirar seu retrato

Pra mim levar (p.14).

Embora sempre acompanhado de algum ritual religioso, observamos pelas leituras dos relatos policiais que esses festejos, sobretudo o cururu, estendiam-se também a outras esferas de sociabilidade, em ajuntamentos apenas para divertimentos.

Seguimos a linha de reflexão da pesquisadora Elisângela de Jesus Santos (2013) que em seus estudos sobre o cururu paulista, faz uma aproximação da dança com o mundo medieval, em articulação entre liturgia e jogo, reza e brincadeira, bem próximo do que ela considera as relações de aproximação e afastamento entre o sagrado e o profano, mantidas entre os povos não brancos convertidos ao cristianismo. Ora, guardadas as diferenças entre o cururu paulista e cururu mato-grossense, considerando o ciclo histórico de ocupação desta região e tendo como suporte outros estudos sobre festas populares que destacam a ocorrência nos processos culturais de comunicação oral "a coexistência, harmoniosa ou não, de uma pluralidade de tradições cujas bases podem ser ocupacionais, étnicas, religiosas etc." (VELHO, 1981, p. 14), consideramos pertinente, nesse ponto, a aproximação com o cururu mato-grossense, que do ponto de vista artístico apresenta-se de forma ordenada e compatível com a realidade católica.

Max Schmidt observou o cururu em Mato Grosso por volta de 1900. Segundo o etnólogo o cururu e o siriri eram muito apreciados em Mato Grosso e eram dançados não só pela "população escura", mas por "pessoas de todas as gradações de cor" (SCHMIDT, 1942. p. 11/14). Max Schmidt observou a dança no município de Rosário Oeste ao norte de Cuiabá, habitado à época pelos índios Borôros e também em Amolar, hoje Mato Grosso do Sul, na fronteira boliviana, habitada à época pelos índios Guatós.

De acordo com seus relatos, a formação inicial do cururu se dava em fileiras, para em seguida se formar o círculo de frente para o altar, onde animados pelos movimentos de revoltear entre si, varavam noite adentro, estimulados pela aguardente de cana. Qual foi sua surpresa ao notar que "enquanto se dançava o cururu dentro de casa, lá fora se realizava outra espécie de dança, muito apreciada em Mato Grosso, o ciriri (sic), acompanhado também por música e versos cantados" (SCHMIDT, 1942. p. 11/14). Apesar de afirmar que essas danças eram muito apreciadas em Mato Grosso, o etnólogo não apresenta maiores detalhes sobre os brincantes.

As descrições ao siriri mato-grossense são raras. Além dessa descrição do etnólogo Max Schmidt, encontramos uma menção à dança, em um jornal local, do dia 13 de abril de 1890, Jornal O Matto Grosso - de publicação semanal, em cuja nota o editor faz duras críticas ao então governador provisório, por ter permitido a presença das "ínfimas camadas do povo" nos jardins do palácio, enquanto a elite festava nos salões da residência. Segue a nota: "Ao que parece impróprio do lugar, do promoter e até mesmo altamente ridículo, foram as danças da arraya miúda, cururu, samba, siriri 
e não sabemos que mais, havidas no jardim, na noite do baile e na seguinte". O editor segue afirmando que estava o "Sr. Marechal Governador sendo agradável com aquela classe de gente que se diverte com tais folguedos", segundo o jornalista, "faltou o decoro de sua posição", pois esse comportamento era considerado uma "exagerada democracia" (1890, p. 03).

Siriri, dançado em pares com formação em círculo ou fileiras, tendo como movimento básico a coreografia das palmas, batem as mãos nas mãos dos dançarinos ora da esquerda ora da direita. Nesse momento de girar a roda, os dançarinos vão respondendo aos tocadores (cururueiros), que conduzem o canto. Na formação em fila se colocam frente à frente, mulheres de um lado, homens de outro, sempre com o movimento de bater as mãos espalmadas nas mãos dos vizinhos. Nesse movimento, a dupla que se encontra em uma das extremidades da fila sai dançando por entre a fileira, nos mais variados ritmos e movimentos, seguidos pelos demais, até que cada par retorne ao seu lugar de origem. A música é simples, porém mais ritmada que a do cururu e varia sobre os temas do cotidiano, bem como sobre os elementos da cultura popular.

O folclorista João Ribeiro (1919) considera o siriri uma dança "generalizada por quase todo o Brasil" (p.227). Segundo sua tradução "o ciriri é o nome de um marisco de concha" (p.227). Associa o siriri brasileiro a uma dança portuguesa do século XVIII, por nome otiriri. Sem maiores detalhes sobre essas danças, o autor aponta os vocábulos ciriri, (correr) e otiriri (que fogo, corre) (p.229), que também são dialetos tupi, suficientes para explicar a sua denominação indígena. De acordo com o autor, pode ter havido uma fusão "contínua e ininterrupta transformação" (p. 231), dessas danças.

Os instrumentos que servem de base sonora para o cururu e o siriri são, a violade-cocho 6 , o ganzá7 e o mocho ${ }^{8}$.

\section{Entre festas e festivais: Perspectivas atuais}

A construção de uma identidade cuiabana, como marco na conciliação entre progresso e civilização, transforma um discurso de ameaças, intimidações e coerções previstos nas Posturas Municipais, à sedução pela originalidade e legitimidade. Ao serem chamados para o palco, para a cena principal, o cururu e o siriri, juntamente com outras práticas culturais, curiosamente recuperados da zona rural, zona portuária e o baixo meretrício, abandonam a periferia e passam a fazer parte das festividades da cidade. $O$ que interessa a partir de então são os modos de fazer dessa arte, uma arte inscrita "nos campos das possibilidades [na qual se] tornam imagináveis, comunicáveis e compreensíveis" (CHARTIER, 2002, p. 91). Ao evocarem tempos imemoriais, seria de estranhar que grupos da elite local obstinados pela construção de uma identidade regional, deixassem de lado manifestações como o cururu e o siriri. Portadores da ideia-chave, da conjunção das raças formadoras da cultura brasileira. Uma cultura advinda de uma sociedade constituída na sua maioria de negros, mestiços e

6 Instrumento de cinco cordas, conquistado a partir da escavação em um tronco inteiriço. Seu processo de construção artesanal, guarda o saber tradicional, cujo registro se encontra no Livro dos Saberes do IPHAN. 2009.

7 Otavio Ramos e Arnaldo Drummond (1978) apresentam o ganzá ou caracachá, na designação antiga. Espécie de reco-reco feito de bambu/ Mario de Andrade (1942) aponta o ganzá como herança africana, instrumento exclusivo de percussão rítmica, trazido nos navios da escravidão.

8 Banco com assento de couro percutido com duas baquetas. 
índios, negligenciada por ser considerada selvagem; no caso dos índios e indigna; no caso dos negros. A recuperação desses tempos e práticas sociais, contou com apoio das instituições públicas e políticos locais, ocasião em que são eleitas; legitimas e genuínas, fundamentais na construção do arcabouço identitário local.

Não seria exagero afirmar que nunca na história de Mato Grosso o cururu e o siriri estiveram tão em evidência. E não há como falar de cururu e siriri sem nos reportarmos ao festival. Digamos que a partir do Festival Cururu e Siriri, que trouxe consigo a presença ostensiva da mídia, os turistas e os patrocinadores, essas danças foram inseridas claramente na era do mercado e do consumo ${ }^{9}$. Vive-se um processo de reinvenção na agenda cultural da cidade, pois o festival oferece aos grupos de cururu e siriri diferentes espaços urbanos e períodos do ano para suas apresentações.

Como consequência do processo de absorção e difusão das festas pelo poder público e privado, que até tempos recentes acontecia somente nos quintais das casas, estas danças passam por intensas transformações na dinâmica interna, seja pela afirmação, aceitação e ampliação por outros públicos, seja na busca por integraremse à realidade global, em um processo próprio de negociação e atualização da cultura popular. Muitos grupos saem do anonimato e precisam repensar o sentido da festa em suas vidas, já que elas se tornam fundamentais para o desenvolvimento local.

O Festival Cururu e Siriri de Cuiabá, nesse contexto, torna-se um dos maiores eventos de cultura popular no Estado. No final do ano de 2001, o Conselho Municipal de Cultura, apresenta uma proposta para uma política cultural na área do folclore (termo usado no documento) cujo objetivo era o de agregar os grupos de cururu e siriri, oriundos da capital e baixada cuiabana ${ }^{10}$. Dentre suas diretrizes estão; proteger e difundir as manifestações da tradição, da memória e da diversidade cultural matogrossense e baixada cuiabana; sem caráter competitivo, estimulando o conhecimento, a formação, capacitação, habilitação e profissionalização ${ }^{11}$.

A cada ano o festival ganhou dimensões significativas, aumentava a participação do público, aumentavam os investimentos e a partir de 2005 o festival ganha características de espetáculo. Em 2007 aconteceu a 6a edição do festival, no qual participaram 31 grupos de siriri e cururu. $O$ festival que aconteceu no bairro do Porto, localizado às margens do rio Cuiabá, mais especificamente no Museu do Rio, antigo ponto de comércio de peixes, especialmente preparado para o festival, contou com a reurbanização de 6.000 mil metros quadrados (aproximadamente), arquibancadas, espaço gourmet, feira de artesanato, banheiros químicos, segurança e estacionamento. Segundo registros na imprensa, passaram pelo local nos quatro dias de festival, cerca de 100 mil pessoas. Em 2008 na 7ํ edição, o palco foi ampliado, a iluminação e sonorização foram reforçadas e contou com a participação de 23 grupos e a presença aproximada de 35 mil pessoas, por dia, nos três dias de festival. No ano seguinte, 2010, o número de participantes subiu para 36 e outro espaço ainda maior, Arena Pantanal. As edições de 2011, 2012, 2013, aconteceram no mesmo espaço que do ano de 2010 e alcançaram um público de aproximadamente 100 mil pessoas em

9 Para Canclini (2008), disseminar as estruturas e os bens simbólicos tradicionais nos circuitos de comunicação em massa, é uma necessidade do mercado em atingir as camadas populares menos integradas à modernidade.

10 Os municípios são: Chapada dos Guimarães, Barra do Bugres, Tangará da Serra, Varginha, Santo Antônio de Leverger, Figueiral, Mimoso, Barão de Melgaço, Nossa Senhora do Livramento, Planalto da Serra, Nova Mutum, Rosário Oeste, Cáceres, Poconé, Várzea Grande, Valo Verde e São Pedro de Joselândia. 11 Ver em Regulamento do Festival de Cururu e Siriri, 2009. 
três dias de festival. Em 2014, participaram 26 grupos. O evento aconteceu durante quatro dias e segundo estimativa dos organizadores, passaram pelo local cerca de 10 mil pessoas por noite de festival. Em 2015 não houve festival em Cuiabá, mas aconteceram eventos no interior do Estado, onde alguns grupos se apresentaram. Outros grupos participaram de eventos fora do Estado. Em 2016 o Festival Cururu e Siriri aconteceu dentro da Feira Internacional de Turismo do Pantanal, um misto de festivais; gastronômico, cultural e de turismo, cujo objetivo era a divulgação das potências do Estado em âmbito nacional e internacional, participaram dois grupos de siriri.

É notório afirmar a partir das observações in loco, que o cururu e o siriri não são hoje o que foram no passado e por outro lado, o que representam não está completamente desvinculado de seu processo histórico. Ao afirmar que toda história é cultural, Chartier (2004) reforça que esse é o sentido da cultura, posto que nada "está acima ou ao lado das relações econômicas e sociais e não existe prática que não se articule sobre as representações pelas quais os indivíduos constroem o sentido de sua existência - um sentido inscrito nas palavras, nos gestos, nos ritos" (p. 18).

Incentivados pelo festival, alguns grupos de siriri assumem definitivamente a ideia de espetáculo e incorporam significativas mudanças. $O$ ritmo é acelerado pela precisão da coreografia, as roupas são padronizadas e ganham brilho, leveza e babados nas saias e nas blusas. Os homens usam camisas com o mesmo tecido dos vestidos das mulheres e calças da mesma cor (ROCHA, 2013). Alguns grupos de cururu também aderiram a ideia das apresentações em festivais, padronizaram suas vestimentas com calça escura, camisas de manga longa em cores claras e sem brilhos. Completam o figurino com chapéu e sapato social (OSORIO, 2012). Apesar das mudanças, se reservam ao aspecto religioso, fazem questão de levar para o palco um andor do santo da devoção e mantém a mesma ordem na dança, em fileiras e depois em roda volteando os corpos da esquerda para a direita. Os desafios cantados contemplam temas de louvor ao santo, que podem ser da tradição ou não. Para o palco; luzes, caixas de som, microfones, amplificadores, arranjos de flores, alegorias de figuras lendárias e os estandartes dos santos. E por último, mas não menos importante, a performance de cada grupo para a abertura da festa.

Atualmente não encontramos mulheres praticando o cururu e não é possível afirmar a partir da bibliografia, em que momento e situação as mulheres deixaram de participar. Entretanto, Moutinho (1869) confirma em seus relatos a presença das mulheres nos brinquedos de cururu "algumas vezes as mulheres fazem parte do cururu, mas cedem logo aos efeitos da cachaça e ficão (sic) prostradas mesmo no lugar da festa até que se dissipe a bebedeira" (p.19). Ramos e Drummond (1978) também registram a presença de mulheres no cururu através de relatos colhidos junto aos cururueiros, "é difícil encontrar uma mulher que consiga ficar rodando a noite inteira, sapateando, bebendo cachaça, e ainda dando conta da viola ou do ganzá. É raro mas acontece" (p. 16). Não obstante, nos processos criminais e nos relatórios produzidos pelos chefes de polícia, constata-se a presença feminina, em situações nas quais o brinquedo era realizado (APEMT, DOC. 03).

Incentivados pelo festival, esses agentes se apropriam desses novos espaços, em um jogo de negociações entre o local e o global. Embora nesse jogo negociado, essas "relações de força não costumam ser igualitárias (...) é evidente que o poder e a 
construção do acontecimento são resultados (...) de múltiplos agentes que se combinam" (CANCLINI 2008, p. 262). Logo, infere-se que os sujeitos não são passivos, não agem como meros espectadores, participam dessas relações de maneira simultânea.

Essa hibridização pelos meios de comunicação é um diferencial do popular no mundo globalizado, estão mais do que nunca presentes na vida cotidiana, social e econômica da cidade, entrelaçando seus produtos culturais aos novos sistemas de comunicação global.

O que quero sublinhar nesta abordagem, é que não se pode ignorar que as transformações sociais da ordem tradicional, caminham tanto em extensão; estabelecendo formas comunicacionais globais, quanto em intensão; em alterar alguns processos cotidianos.

\section{REFERÊNCIAS}

AMERICANO do BRASIL, Antônio. Cancioneiro de trovas do Brasil Central. Goiânia, GO. Oriente, $2^{\underline{a}}$ ed. 1973.

ANDRADE, Mário de. Pequena história da música. 2ª ed. Martins, São Paulo. 1942.

CANCLINI, Nestor Garcia. Culturas hibridas: Estratégias para entrar e sair da modernidade - 4 ed. São Paulo - Ensaios Latino-americanos, 1. 2008.

CÂNDIDO, Antônio. Possíveis raízes indígenas de uma dança popular. In: Leituras de etnologia brasileira. Shaden Egon. São Paulo: Cia Ed. Nacional, 1976.

CERTEAU, Michel de. A Escrita da História. trad. Maria de Lourdes Menezes. Rio de Janeiro: Forense Universitária, 1982.

CHARTIER, Roger. À beira da falésia: a história entre certezas e inquietudes. Porto Alegre: UFRGS, 2002.

1945-Leituras e leitores na França do Antigo Regime. Tradução: Álvaro Lorencini. São Paulo. Ed. UNESP. 2004.

DEBORD, Guy. A Sociedade do Espetáculo (1931-1994) - Coletivo Periferia. 2003.

GUSHIKEN, Yuji. Folkcomunicação nas relações socioeconômicas e políticas contemporâneas. In: Intercom - Sociedade Brasileira de Estudos Interdisciplinares da Comunicação - XXXII Congresso Brasileiro de Ciências da Comunicação. 2009. pp. 01/15.

IPHAN - Modo de fazer Viola de Cocho- Brasília, DF. 2009.

MACHADO FILHO, Oswaldo. Ilegalismos e jogos de poder: um crime célebre em 
Cuiabá (1872) suas verdades jurídicas e outras histórias policiais. Tese Doutorado UFMT- Cuiabá/MT, Ed. UFMT. 2006.

MAGALHÃES, Couto de. 7ª Conferencia -Tricentenário de Anchieta - Anchieta, as raças e línguas indígenas. São Paulo. 1897.

MOUTINHO, Joaquim Ferreira. Notícia sobre a província de Matto Grosso seguida d'um roteiro da viagem da sua capital à S. Paulo. São Paulo: Typographia de Henrique Schroeder. 1869.

OSÓRIO, Patrícia Silva. Os festivais de Cururu e Siriri: Mudanças de cenários e contextos na cultura popular - In: Anuário Antropológico. 2012. pp. 237/260.

RAMOS, Otávio; DRUMMOND, Arnaldo F. Função do Cururu. Cadernos Cuiabanos - 8. Ed. Planimpress. São Paulo. 1978.

RIBEIRO, João. O folk-lore: estudos de literatura popular. Rio de Janeiro: Jacinto Ribeiro dos Santos, 1919.

ROCHA, Anderson. Política e Cultura em Mato Grosso: Considerações sobre estratégias de construção de uma identidade local. In: XXVII Simpósio Nacional de História. Conhecimento histórico e diálogo social. 2013.

SANTOS, Elisângela de Jesus. Entre Improvisos e Desafios: do cururu como cosmovisão de grupos caipiras no Médio Tietê, SP. Tese (Doutorado em Ciências Sociais) - Universidade Estadual Paulista, Faculdade de Ciências e Letras - Campus de Araraquara. 2013.

SCHMIDT, Max. Estudos de etnologia brasileira; peripécias de uma viagem entre 1900 e 1901 e seus resultados etnológicos. São Paulo. Companhia Editora Nacional. 1942.

STEINEN, Karl von den. Entre os aborígenes do Brasil central. São Paulo: Dep. De Cultura, 1940.

TRIGUEIRO, Osvaldo Meira. A espetacularização das culturas populares ou produtos culturais folkmidiáticos. In: Culturas Populares, Circuitos de Difusão de Mercados. Seminário Nacional de Políticas Públicas - São Leopoldo. RS. 2005, pp. 01/09.

VELHO, Gilberto. Projeto, emoção e orientação em sociedades complexas. In Individualismo e cultura. Rio de Janeiro, Zahar. 1981.

VERDELHO, Telmo dos Santos, SILVESTRE, João Paulo. Lexicografia Bilíngue A tradição dicionarística português - línguas modernas. Gráfica de Coimbra - 
Aveiro - Lisboa. 1aㅡ ed. 2011.

VOLPATO, Luiza Rios Ricci. Cativos do sertão: vida cotidiana e escravidão em Cuiabá em 1850-1888. São Paulo: Editora Marco Zero. 1993.

\section{MANUSCRITOS}

DOC. 01 - APEMT - Posturas Policiais da Câmara Municipal da Cidade de Cuiabá, ano de 1831- Fundo: Câmara; Grupo: Códigos de Posturas - Originais; Caixa 01.

DOC. 02 - APEMT - Relatório enviado pelo chefe de polícia da província de Mato Grosso, Jesuino de Souza Martins, ao presidente da mesma província, Antonio Pedro de Alencastro, em 16 de dezembro de 1860. Fundo: Poder Judiciário Estadual; Grupo: Cartório do 6ㅇ́́ㄷo; Subgrupo: Série Penal; Documentos Avulsos. Mantida a ortografia da época.

DOC. 03 - APEMT - Relatório do Chefe de Polícia - Fundo: Poder Judiciário Estadual; Grupo: Cartório do 6 Ofício; Subgrupo: Penal; Série: Sumário de Culpa; Subsérie: Ferimento [Lesão Corporal]. Ano 1866.

Parece ter sido o escravo Benedito o organizador do cururu realizado na casa de Escolastica Maria Joaquina, em 23 de setembro de 1866. Contudo, Escolastica, Maria Luisa, Victoriana Padilha e Pocidonia também foram presas sob a acusação de terem sido coniventes no divertimento, que não possuía autorização da câmara.

\section{FONTES ACESSADAS NA INTERNET}

AGORA MATO GROSSO. Cidades. Cururu e siriri em Lucas do Rio Verde. <http://www.mtagora.com.br/cidades/cururu-e-siriri-marcam-abertura-defestival-de-cultura-na-proxima-sexta-feira-em-lucas/90450480>. Acesso em 08/08/2016.

G1. PORTAL DE NOTÍCIAS. Mato Grosso.

<http://g1.globo.com/mato-grosso/noticia/2016/04/programacao-da-fit-pantanal-em-cuiaba-comeca-16h-neste-sabado.html.> Acesso em 08/08/2016.

JORNAL O Matto-Grosso. 1890. <http://memoria.bn.br/DOCREADER/DocReader.aspx ?bib=716189\&PagFis=0\&Pesq= Acesso em 06/11/2016>. Grifos meus.

OLHAR DIRETO. Notícias - Festival.

<http://www.olhardireto.com.br/conceito/noticias/exibir.asp?noticia=grupode-siriri-vende-canecas-para-conseguir-participar-de-festival-no-rj-e-levacinco-premiosfid=10738>. Acesso em 08/08/2016. 
REGULAMENTO do Festival de Cururu e Siriri. In: Conselho Municipal de Cultura de Cuiabá. Central de Texto, 2009. <https://10festivalcururusiriri.wordpress.com/2011/10/26/regulamento-do-10festival-cururu-siriri>. Acesso em 01/08/2016. 